\title{
EXPLORATION OF THE
}

PLANETARY SYSTEM

Edited by A. WOSZCZYK and C. IWANISZEWSKA
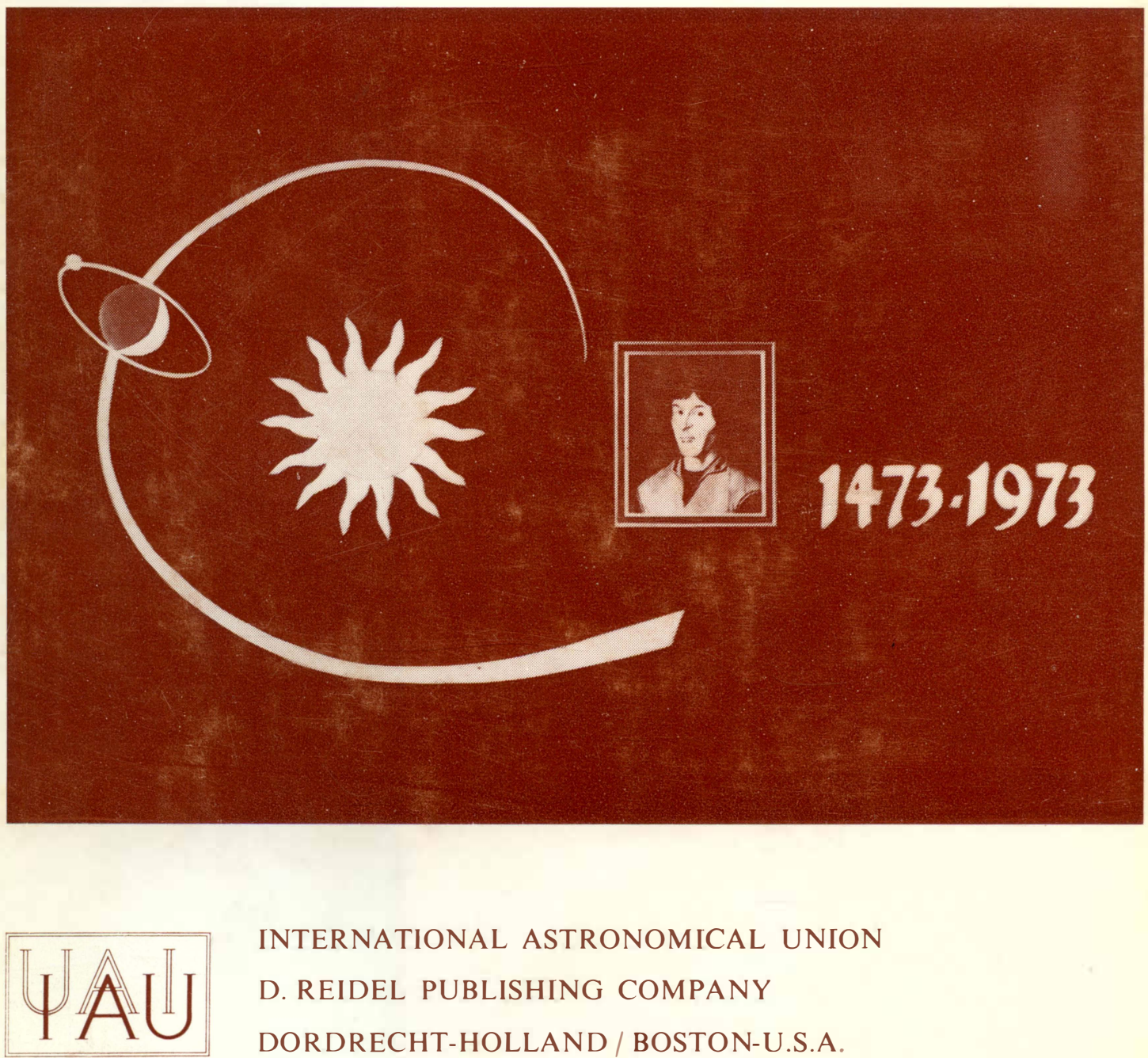

INTERNATIONAL ASTRONOMICAL UNION

D. REIDEL PUBLISHING COMPANY

DORDRECHT-HOLLAND / BOSTON-U.S.A. 
EXPLORATION OF THE

PLANETARY SYSTEM

SYMPOSIUM No. 65

The I.A.U. Symposium No. 65, devoted to the contemporary knowledge of the world of Copernicus - the planetary system, was held in Copernicus' native town, Toruń, Poland, from 5th to 8th September 1973 as part of the Extraordinary General Assembly of the I.A.U. in commemoration of the 500th anniversary of the birth of Nicolaus Copernicus. 18 invited review papers and 33 contributions dealing with the general considerations about the origin and physics of the planetary system (6), terrestrial planets (18), and giant planets and their satellites (22) were presented. These problems were considered on the basis of optical and radio observations from the ground and from space. A special session devoted to the laboratory research of interest in the interpretation of spectroscopic, photometric and polarimetric observations of planets was organized. The plans of further exploration of the planetary system were discussed.

D. REIDEL PUBLISHING COMPANY

DORDRECHT-HOLLAND / BOSTON-U.S.A. 
EXPLORATION OF THE PLANETARY SYSTEM 
INTERNATIONAL ASTRONOMICAL UNION

UNION ASTRONOMIQUE INTERNATIONALE

SYMPOSIUM No. 65

(COPERNICUSS SYMPOSIUM IV)

HELD IN TORUŃ, POLAND, 5-8 SEPTEMBER, 1973

\title{
EXPLORATION OF THE PLANETARY SYSTEM
}

\author{
EDITED BY \\ A. WOSZCZYK AND C. IWANISZEWSKA \\ Astronomical Observatory of Nicolaus Copernicus University, Toruń, Poland
}

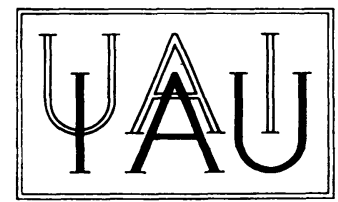

D. REIDEL PUBLISHING COMPANY

DORDRECHT-HOLLAND / BOSTON-U.S.A.

1974 


\author{
Published on behalf of \\ the International Astronomical Union \\ by \\ D. Reidel Publishing Company, P.O. Box 17, Dordrecht, Holland
}

All Rights Reserved

Copyright 01974 by the International Astronomical Union

Sold and distributed in the U.S.A., Canada, and Mexico

by D. Reidel Publishing Company, Inc.

306 Dartmouth Street, Boston,

Mass. 02116, U.S.A.

Library of Congress Catalog Card Number 73-94458

Cloth edition: ISBN $902770449 \mathrm{X}$

Paperback edition: ISBN 9027704503

No part of this book may be reproduced in any form, by print, photoprint, microfilm. or any other means, without written permission from the publisher

Printed in The Netherlands by D. Reidel, Dordrecht 


\section{0th ANNIVERSARY \\ OF THE BIRTH OF NICOLAUS COPERNICUS}

1473-1973 
ORGANIZING COMMITTEE X X

PREFACE $\quad$ XI

INAUGURAL ADDRESS BY WITOLD LUKASZEWICZ XIII

\section{PART I/ORIGIN AND GENERAL PHYSICS OF THE PLANETARY SYSTEM}

I. P. Williams / Planetary Formation

W. F. HUEBNER and L. W. FULLERTON / Status of Molecular Opacities of Interest in the Modeling of a Proto-Solar Nebula

A. CARUSI, A. CORADINI, C. FEDERICO, M. FULCHIGNONI, and G. MAGNI/On the Growth Mechanism of Grains in a Primordial Stage of the Solar Nebula

D. H. MENZEL / The Escape of Planetary Atmospheres

K. NARAHARI RAO / Modern Research in High Resolution Infrared Spectroscopy and Its Importance to Planetary Physics

D. Williams / Optical Properties of Particles in Planetary Atmospheres:

Laboratory Studies

J. HANASZ, V. I. AKSENOV, and G. P. KOMRAKOV / First Results of the Soviet-Polish Space Experiment 'Intercosmos-Kopernik 500'

\section{PART II/ TERRESTRIAL PLANETS}

L. G. YOUNG / Infrared Spectra of Venus

M. A. JANSSEN / Radio Interferometry of Venus at Short Wavelengths

Y. FOUQUART / Profondeur de pénétration et formation des raies dans une atmosphère diffusante

C. BIGOURD, J. L. DEUZE, C. DEVAUX, M. HERMAN, et J. LENOBLE / Etude théorique de la répartition de luminance sur le disque de Venus

E. M. FEIGELSON, N. L. LUKASHEVICH, G. M. KREKOV, and G. A. TYTOV /

Numerical Modelling of the Reflection Spectrum of Venus in the Visual and Near Infrared Ranges

E. M. FEIGELSON, N. L. LUKASHEVICH, and M. Ya. MAROV / Interpretation of the Illumination Measurements by the Automatic Interplanetary Station 'Venera 8'

J. E. HANSEN and J. W. Hovenier / Nature of the Venus Clouds as Derived from Their Polarization 
T. R. GULL, C. R. O'DELL, and R. A. R. PARKER / Water Vapor in Venus Determined by Airborne Observations of the $8200 \AA$ Band

E. S. BARKER / Ground-Based Observations of Mars and Venus Water Vapor during 1972 and 1973

W. A. TRAUB and N. P. CARLETON/Observations of $\mathrm{O}_{2}, \mathrm{H}_{2} \mathrm{O}$ and HD in Planetary Atmospheres

R. BEER / The Spectrum of Mars in the Region 1800-3200 $\mathrm{cm}^{-1}$

W. A. BAUM / Results of Current Mars Studies at the IAU Planetary Research Center

A. T. YOUNG / UBV Photometry of Mars

V. V. BOTVINOVA, O. I. BUGAENKO, I. K. KOVAL, M. K. NARAJEVA, and A. S. SElivanov / Photometric Data from Some Photographs of Mars Obtained with the Automatic Interplanetary Station 'Mars 3'

J. PEARL, B. CONRATH, R. CURRAN, R. HANEL, V. KUNDE, and J. PIRRAGLIA / Results from the Infrared Spectroscopy Experiment on Mariner 9

A. J. KLIORE / Radio Occultation Exploration of Mars

G. I. BARENBLATT and G. S. GOLITSYN / Mars: Local Structure of Dust Storms

PART III/OUTER PLANETS AND THEIR SATELLITES

D. GAUTIER / The Hydrogen to Helium Mixing Ratio in the Giant Planets

R. S. HAW KE / On the Equation of State of Hydrogen and Its Use in Models of Major Planets

H. C. GRA BOSKE, JR. / The Influence of the Surface Boundary Layer on Evolutionary Models of Jupiter

N. P. CARLETON and W. A. TRAUB / Observations of Spatial and Temporal Variations of the Jovian $\mathrm{H}_{2}$ Quadrupole Lines

R. DUYSINX and M. HENRIST / TDIA Satellite Spectroscopic Observations of Jupiter in the Ultraviolet

C. DE BERGH, M. COMBES, TH. ENCRENAZ, J. LECACHEUX, M. VION, and J. P. MAILLARD / New Infrared Spectra of the Jovian Planets: Study of Jupiter and Saturn in the $3 v_{3}$ Methane Band by Fourier Transform Spectroscopy

K. FOX / On the Microwave Spectrum of Methane in the Atmospheres of the Outer Planets

S. GULKIS, M. J. KLEIN, and R. L. POYNTER / Jupiter's Microwave Spectrum: Implications for the Upper Atmosphere

J. J. DEGIOANNI and J. R. DICKEL / Jupiter's Radiation Belts and Upper Atmosphere

G. E. HUNT and J. T. BERGSTRALH / Analysis of Spectroscopic Observations of Jupiter and the Variability of the Structure of the Visible Clouds

R. HIDE / Motions in Jupiter's Atmosphere 
L. VAPILLON / Results of the Beta Scorpii Occultation by Jupiter on May 13, 1971

R. W. ShORThill, T. F. GReene, and D. W. SMITh / Atmospheric Properties of Jupiter Determined from Galilean Satellite Eclipse Light Curves

C. H. BARROW / Millisecond Polarized Pulses in Decametre-Wave Radiation from Jupiter and Sun

V. G. TEIFEL / The Atmosphere of Saturn

Y. KA W A TA and W. M. IR VINE / Models of Saturn's Rings which satisfy the Optical Observations

M. S. BOBROV / A Study of the Outermost Ring of Saturn

M. DENNEFELD / Theoretical Studies of an Atmosphere Around Saturn's

\section{Rings}

T. R. MCDONOUgh and N. BRICE/ The Saturnian 'Gas-Doughnut' Hypothesis

TH. ENCRENAZ, J. HARDORP, T. OWEN, and J. H. 'WOODMAN / Observational Constraints on Model Atmospheres for Uranus and Neptune

L. TRA FTON / Neptune: Observations of the $\mathrm{H}_{2}$ Quadrupole Lines in the (4-0) Band

A. DOLLFUS et J. B. MURRAY / La rotation, la cartographie et la photométrie des satellites de Jupiter

R. A. B ROW N / Optical Line Emission from Io

C. BLANCO and S. CATALANO / Relation Between Light Variations of Solar System Satellites and Their Interaction with Interplanetary Medium

PART IV / FUTURE EXPLORATIONS OF THE SOLAR SYSTEM

A. MONFILS and J. C. GÉRARD / Spectroscopic Observations of Venus

T. GEHRELS / Photopolarimetry of Planets

I. RASOOL, D. HERMAN, D. KERRISK, and W. BRUNK / Rationale for NASA Planetary Exploration Program 